\title{
CONCURRENT EXPRESSION OF PROCOAGULANT AND PLASMINOGEN ACTIVATOR ACTTVITIES BY RABBIT ALVEOLAR MACROPHAGES IN VITRO: OPPOSITE MODULATING EFFECTS OF PROSTAGLANDIN E 2
}

\author{
Jeffrey D. Hasday and Robert G. Sitrin \\ From the Pulmonary and Critical Care Medicine Division \\ Department of Internal Medicine \\ University of Michigan Medical Center \\ Ann Arbor, Michigan 48109-0360 U.S.A. \\ (Received 18.6.1987; accepted in revised form 20.4.1988 \\ by Editor N.U. Bang) \\ (Received in final form by Executive Editorial office 23.6.1988)
}

\section{ABSTRACT}

We examined the effects of arachidonic acid metabolites on the simultaneous expression of procoagulant (PC) and plasminogen activator (PA) activities by rabbit alveolar macrophages. Incubation with lymphocyte-conditioned medium (LCM) caused a significant increase in cell-associated PC activity. Co-treatment with indomethacin $(1 \mu \mathrm{M})$ reduced this augmentation in PC activity by $33 \%(\mathrm{p}<0.05)$. In contrast, indomethacin caused a $42 \%$ increase in PA activity released into incubation medium $(\mathrm{p}<.05)$. Both effects of indomethacin were reversed by the addition of $\mathrm{PGE}_{2}$ in concentrations as low as $1 \mathrm{nM}$. Addition of $100 \mathrm{nM} \mathrm{PGE}$ to these cells caused an increase in PC activity 2.7-fold greater than that achieved by LCM alone, while $\mathrm{PGE}_{2}$ suppressed released PA activity by $62 \% . \mathrm{PGE}_{2}$ and indomethacin had similar but less pronounced effects on phorbol myristate acetate-treated cells. These effects of $\mathrm{PGE}_{2}$ could be duplicated by $P G E_{1}$, but not by any other arachidonic acid metabolite $\left(\mathrm{PGF}_{2} \alpha, \mathrm{PGI}_{2}, \mathrm{PGD}_{2}, \mathrm{ddPGF}_{2} \alpha, \mathrm{LTB}_{4}\right.$, or $\left.\mathrm{LTC}_{4}\right)$. While $\mathrm{PGE}_{2}$ increases intracellular levels of cAMP, the observed effects on PC and PA activities could not be reproduced fully by treatment with dibutyryl cAMP. We conclude that $\mathrm{PGE}_{2}$ amplifies the augmentation of PC activity by stimulated alveolar macrophages while concurrently inhibiting expression of plasminogen activator. This suggests that $\mathrm{PGE}_{2}$ may be a significant mediator in regulating the highly interactive processes of inflammation and coagulation/fibrinolysis.

\section{INTRODUCTION}

Arachidonic acid metabolites are increasingly recognized as important in regulating expression of inflammatory responses (1-16). We previously demonstrated that prostaglandin $(\mathrm{PG}) \mathrm{E}_{2}$ is necessary for the augmented expression of procoagulant (PC) activity by rabbit alveolar macrophages stimulated by bacterial lipopolysaccharide. This observation led us to hypothesize that $\mathrm{PGF}_{2}$ may represent an important regulatory link between inflammatory and coagulation pathways (17). However, macrophages also promote fibrinolysis, chiefly by elaborating a

Key Words: Macrophage, procoagulant, plasminogen activator, arachidonic acid 
plasminogen activator (PA) $(18,19)$. Thus, the net effect of macrophages on fibrin turnover during inflammation must be viewed in the context of the simultaneous expression of competing procoagulant and fibrinolytic activities. Because there is limited evidence that $\mathrm{PGE}_{2}$ suppresses plasminogen activator activity of elicited macrophages $(20,21)$, we undertook to expand our earlier study by examining the role of cyclooxygenase and lipoxygenase metabolites on the concomitant expression by macrophages of both procoagulant and plasminogen activator activities.

\section{METHODS}

Animals - Male New Zealand white rabbits (1.5 to $2 \mathrm{~kg}$ ) were given routine care in the Unit for Laboratory Animal Medicine, University of Michigan Medical Center.

Bronchoalveolar Lavage - Rabbits were sacrificed by intravenous injection of sodium pentobarbital and exsanguinated prior to lavage. The trachea was cannulated and the lungs lavaged with $35 \mathrm{ml}$ aliquots of Dulbecco's calcum-magnesium-free phosphate buffered saline (PBS; Gibco, Grand Island, NY) at $37^{\circ} \mathrm{C}$ until $300 \mathrm{ml}$ of lavage fluid was returned. Cell pellets were treated with 110 $\mathrm{mM}$ ammonium chloride in $100 \mathrm{mM}$ Tris buffer $(\mathrm{pH} 7.0)$ to lyse contaminating erythrocytes. The cells were then washed three times in serum-free culture medium consisting of RPM1-1640 (Gibco) containing penicillin $(100 \mathrm{U} / \mathrm{ml})$, streptomycin $(100 \mu \mathrm{g} / \mathrm{ml})$, gentamicin $(100 \mu \mathrm{g} / \mathrm{ml})$, polymixin B $(100 \mathrm{U} / \mathrm{ml})$, and lactalbumin hydrolysate $(0.2 \%$, Gibco). In all cases, cell viability was greater than $95 \%$ by trypan blue exclusion. Cell preparations were consistently more than 95\% alveolar macrophages (22).

Preparation of Additives. Lymphocyte-conditioned medium (LCM) was used as a crude source of lymphokines. Lymphocyte suspensions were prepared from normal rabbits as described previously (19). Cell suspensions were prepared in standard culture medium from the nonadherent cells of minced paraortic lymph nodes ( $>95 \%$ lymphocytes) and incubated in $75 \mathrm{ml}$ culture flasks (Falcon Labware, Oxnard, CA) for 48 hours at $5 \times 10^{6} \mathrm{cell} / \mathrm{s} / \mathrm{ml}$ in medium containing Concanavalin A bound to Sepharose 4B beads $(5 \mu \mathrm{g} / \mathrm{ml}$ Con A; Pharmacia Chemicals, Piscataway, NJ). After incubation, the LCM was freed of cells and Con A-Sepharose by centrifugation, sterilized by filtration, and stored at $-70^{\circ} \mathrm{C}$. Preliminary experiments indicated that a 1:8 dilution of LCM was optimal, and one such preparation was used in all subsequent experiments. Prostaglandins (PG) and leukotrienes (LT) were generous gifts of the Upjohn Corporation, Kalamazoo, MI. All were stored at $-20^{\circ} \mathrm{C}$ in ethyl alcohol. Indomethacin (Sigma) was freshly dissolved in ethyl alcohol $(10 \mathrm{mg} / \mathrm{ml})$. All additives were further diluted in culture medium such that the final concentration of ethyl alcohol in cell cultures did not exceed $0.01 \%$. The semiselective lipoxygenase inhibitors nordihydroguiaretic acid (NDGA; Aldrich Chemicals, Milwaukee, WI) and nafazatrom (Burroughs Wellcome, Research Triangle, NC) were dissolved directly in culture medium. Phorbol myristate acetate (PMA; Consolidated Midland, Brewster, $\mathrm{NY}$ ) was stored at $-20^{\circ} \mathrm{C}$ dissolved $(1 \mathrm{mg} / \mathrm{ml})$ in dimethylsulfoxide (DMSO) and freshly diluted in culture medium for each experiment so that the final DMSO concentration did not exceed 10 parts per million.

Cell Culture. One million cells were dispensed in $1 \mathrm{ml}$ of the serum-free culture medium and incubated in duplicate in sterile $12 \times 75 \mathrm{~mm}$ polypropylene tubes for 24 hours at $37^{\circ} \mathrm{C}$ in $5 \% \mathrm{CO}_{2}-$ enriched air. Cells were exposed to the various additives for the entire incubation period, as indicated. Following incubation, the cells were collected by centrifugation and resuspended in 1 $\mathrm{ml}$ of fresh medium. Both cell suspensions and conditioned incubation media were stored at $-20^{\circ} \mathrm{C}$ prior to assay. Cell lysates were prepared for assay by two cycles of freeze-thawing followed by sonication.

Procoagulant Activity Assay. Procoagulant activity was measured using a one-stage coagulation assay (22). Briefly, $100 \mu \mathrm{l}$ volumes of test material, $25 \mathrm{mM} \mathrm{CaCl}$, and citrated normal rabbit plasma were mixed sequentially at $37^{\circ} \mathrm{C}$ and the time required for fibrin formation was measured with a coagulation timer (BBL Fibrosystem, Cockeysville, MD). Coagulation times of each sample were measured twice and averaged (measurements consistently agreed within 10-15\%). 
The means of the duplicate samples were then translated into arbitrary units of PC activity using a standard curve based on the linear relationship between the log concentration of procoagulant material and the log of the resultant coagulation time (22). Preliminary experiments confirmed our prior observations that only a small fraction of the PC activity generated by these cells was released into the culture medium, and that the released activity varied in parallel with cell-associated activity (22). Accordingly, we routinely assayed PC activity only in cell lysates. None of the pharmacologic agents used in the study affected the assay for PC activity.

Plasminogen Activator Assay. PA activities of incubation media and cell lysates were measured with a modified ${ }^{125} \mathrm{I}$-fibrin plate assay, as described previously in detail $(18,19)$. In brief, $60 \mu \mathrm{g}$ of human fibrinogen (Kabi, Stockholm, Sweden) containing $2 \times 10^{5} \mathrm{cpm}$ of 125 I-labeled fibrinogen (Amersham, Arlington Hts, IL) was dried onto $16 \mathrm{~mm}$ plastic culture wells and converted to fibrin with $5 \%$ fetal bovine serum (Gibco). Human plasminogen was purified by lysine-Sepharose affinity chromatography (23) and added in an optimal concentration ( 2 to $6 \mu \mathrm{g}$ protein $/ \mathrm{ml}$ ) along with test samples to the fibrin wells. ${ }^{125}$ I activity released into the incubation medium was measured after 4 hours at $37^{\circ} \mathrm{C}$. The cpm released only in the presence of test sample and plasminogen was taken to represent PA activity. Net ${ }^{125}$ I release was calculated as the percent of maximal release achieved by trypsinizing the wells; percent lysis was then translated into milliPlough units (mPU) using a standard curve generated with human urokinase (Sigma Chemicals, St. Louis, MO). ${ }^{125}$ I release was negligible in the absence of added plasminogen; therefore, plasminogen-independent fibrinolysis was not examined further. None of the pharmacologic interventions affected the ${ }^{125} \mathrm{I}$-fibrin assay. It is important to emphasize that this assay only measures plasminogen-dependent fibrinolysis, and the results may reflect changes in either plasminogen activator proteins or plasminogen activator inhibitors. Therefore, PA is only discussed in terms of activity, and not concentrations of specific proteins.

Cyclic Adenosine Monophosphate (cAMP) Assay. Intracellular cAMP levels were measured with a double antibody radioimmunoassay (24). The limit of sensitivity was $10 \mathrm{fmole} / \mathrm{ml}$, and interand intra-assay variabilities were $2.7 \%$ and $2.9 \%$, respectively. This assay only cross-reacted with 6-fold greater concentrations of adenosine monophosphate and at least 400 -fold greater concentrations of other purine nucleosides and nucleotides. Assays were performed by the laboratories of the Diabetes Training and Research Center, University of Michigan Medical Center.

Statistics. Multiple comparisons to control groups were performed using Dunnett's test applied to a one-way analysis of variance. Single comparisons were tested with the unpaired Student's t test (25).

\section{RESULTS}

Procoagulant and plasminogen activator activities of normal and stimulated macrophages. In keeping with our previous studies $(19,22)$, freshly isolated alveolar macrophages expressed both procoagulant and plasminogen activator activities (Table 1). Cell lysates accelerated coagulation of normal plasma to $197 \pm 31.6 \mathrm{~s}$, compared to spontaneous coagulation times of recalcified plasma consistently greater than $500 \mathrm{sec}$. When cells were incubated for 24 hours in standard culture medium, there was a modest but significant increase in PC activity $(105 \pm 7.7 \mathrm{sec} ; \mathrm{p}<0.001)$. The addition of LCM to the culture medium caused a further increase in PC activity (88.5 \pm 6.7 sec; $\mathrm{p}<0.05)$. Maximal stimulation with PMA $(10 \mathrm{nM})$ caused a marked increase in procoagulant activity $(47.1 \pm 3.6 \mathrm{sec} ; \mathrm{p}<0.001)$. Prior studies have shown that this procoagulant activity functions as a tissue thromboplastin, activating the extrinsic coagulation pathway (22).

Lysates of freshly isolated macrophages expressed low levels of plasminogen activator activity $\left(93.8 \pm 25 \mathrm{mPU} / 10^{6}\right.$ cells). When cells were cultured for 24 hours, the lysate activity increased to $358 \pm 84 \mathrm{mPU} / 10^{6}$ cells $(\mathrm{p}<0.001)$. In addition, $642 \pm 155 \mathrm{mPU} / \mathrm{ml}$ was present in the culture medium. LCM did not affect expression of PA in either lysates or incubation media $(p>0.5)$, but PMA caused marked increases in both activities (Table 1). We have shown that this plasminogen activator has immunologic and molecular weight characteristics of a urokinase rather than a tissue plasminogen activator (26). Preliminary experiments (not shown) verified that the effects of LCM 
and PMA on PC and PA activities were not affected by the presence or absence of polymyxin B, indicating that the effects were not due to contaminating endotoxin (17).

TABLE 1: Procoagulant and Plasminogen Activator Activities of Normal and Stimulated Rabbit Alveolar Macrophages*

\begin{tabular}{|c|c|c|c|c|}
\hline Stimulus & $\begin{array}{r}\text { Incubation } \\
\text { Time (h) }\end{array}$ & $\begin{array}{c}\text { Coagulation } \\
\text { Time (sec) }\end{array}$ & \multicolumn{2}{|c|}{ Plasminogen Activator } \\
\hline & & & $\begin{array}{c}\text { Lysates } \\
\text { (mPU/10 cells) }\end{array}$ & $\begin{array}{c}\text { Media } \\
(\mathrm{mPU} / \mathrm{ml})\end{array}$ \\
\hline Medium (no cells) & & $>500$ & & -.----- \\
\hline 0 & 0 & $197 \pm 31.6$ & $93.8 \pm 25$ & -.----- \\
\hline 0 & 24 & $105 \pm 7.7$ & $358 \pm 84$ & $642 \pm 155$ \\
\hline Lymphokine & 24 & $88.5 \pm 6.7$ & $472 \pm 237$ & $510 \pm 149$ \\
\hline PMA & 24 & $47.1 \pm 3.6$ & $2666 \pm 326$ & $9275 \pm 2026$ \\
\hline
\end{tabular}
*Mean \pm SEM, $N=4-12$
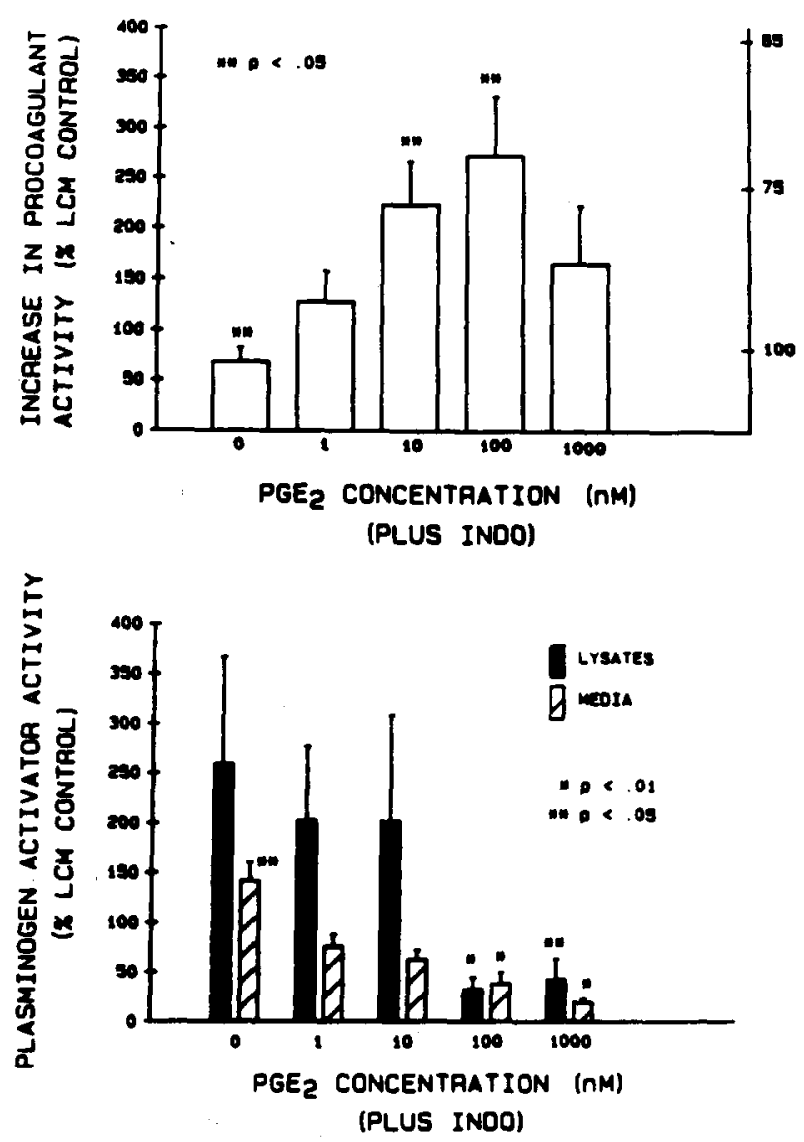

Eigure 1. Effects of indomethacin $(1 \mu \mathrm{M})$ and $\mathrm{PGE}_{2}$ on expression of $\mathrm{PC}$ and PA activities by rabbit alveolar macrophages stimulated with lymphocyte conditioned medium. Data are expressed as the \% of control values from cells cultured with $\mathrm{LCM}$ alone. Mean $\pm \mathrm{SEM}, \mathrm{N}=6$, except for $100 \mathrm{nM} \mathrm{PGE}_{2}$, where $\mathrm{N}=12$. A single asterisk denotes $\mathrm{p}<0.01$. Two asterisks denote $\mathrm{p}$ $<0.05$. TOP: PC activity. The increase in PC activities above levels of freshly-harvested cells is displayed on the ordinate at the left. Corresponding coagulation times are shown at the right (log scale). Indomethacin suppressed the increase in PC activity by $33 \%$. As little as $1 \mathrm{nM} \mathrm{PGE}_{2}$ reversed this effect and an optimal dose stimulated an increase in PC activity 2.7 fold greater than control values. BOTTOM: PA activity. Indomethacin increased release of PA activity to $142 \%$ of control values, and the addition of $\mathrm{PGE}_{2}$ suppressed $\mathrm{PA}$ activities in cell lysates and incubation media to as little as $33 \%$ and $20 \%$ of controls, respectively. 
Effects of cyclooxygenase products on PC and PA activities of LCM-treated cells. Co-treatment with indomethacin $(1 \mu \mathrm{M})$ blunted the LCM-stimulated increase in PC activity by $33 \%(\mathrm{p}<0.05$; Figure 1A) This corresponded to prolongation in coagulation times to $100.1 \pm 6.1$ seconds $(\mathrm{p}<$ 0.1 ). The inhibitory effects of indomethacin were completely reversed by the addition of $\mathrm{PGE}_{2}$ in concentrations as low as $1 \mathrm{nM}$. Higher concentrations of $\mathrm{PGE}_{2}$ further augmented the resultant PC activity, with $100 \mathrm{nM}$ concentrations stimulating almost 3-fold greater $\mathrm{PC}$ activity compared to cells treated with LCM alone (Figure 1A). This represented a decrease in coagulation times to 72.6 \pm 3.6 seconds $(p<0.001)$. Neither indomethacin nor $P G E_{2}$ alone altered $P C$ activity unless a conditioning stimulus such as LCM was present, confirming our prior observations (17).

The PA activities in lysates and incubation media from control cells were variable, but indomethacin caused consistent and significant increases in PA activity released into incubation media, reaching $142 \%$ of control values ( $p<0.05$; Figure 1B). Addition of $P_{G E}$ in doses as low as $1 \mathrm{nM}$ reversed the effect of indomethacin, while higher concentrations caused further suppression of PA activity. The effect was dose-related, with $100 \mathrm{nM} \mathrm{PGE}_{2}$ maximally suppressing both cell-associated and released PA activities to $33 \%$ and $38 \%$ of controls, respectively ( $p<0.01$ ). In time course studies, the effects of $P G E_{2}$ on $P C$ and PA activities both appeared after incubation for 8 hours. Unlike the augmentation of $P C$ activity, the suppression of $\mathrm{PA}$ activity by $\mathrm{PGE}_{2}$ did not require co-treatment with a conditioning stimulus such as LCM, as identical suppressive effects were seen when $\mathrm{PGE}_{2}$ was added alone to normal rabbit alveolar macrophages (not shown).

To determine if augmentation of $P C$ and suppression of PA activities were specific to $\mathrm{PGE}_{2}$, macrophages were incubated with $L C M$, indomethacin $(1 \mu \mathrm{M})$, and $P G E_{2}, P_{1}, P_{1} F_{2} \alpha, P_{2}$,

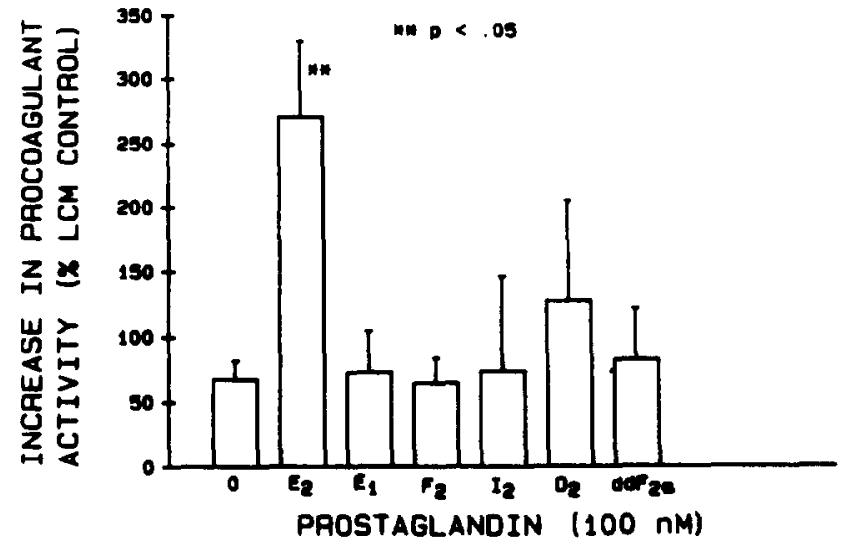

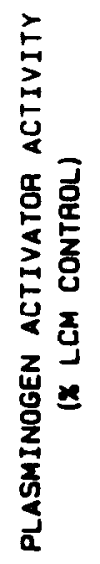

(PLUS LCM AND INDO)

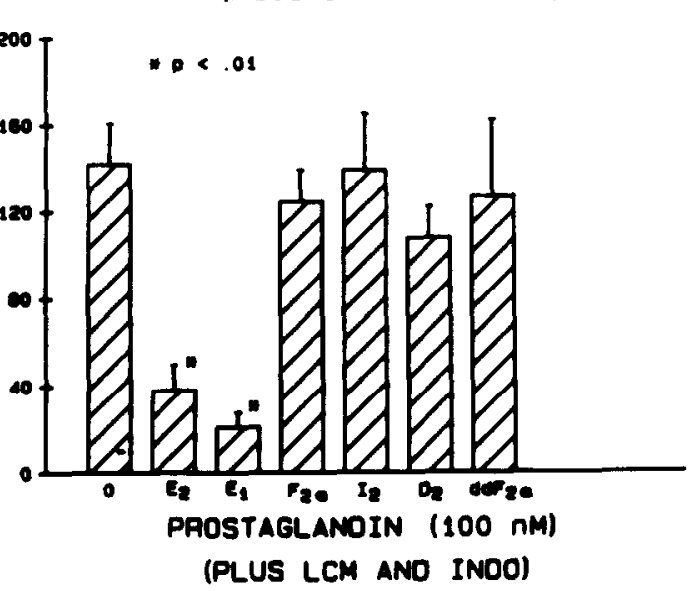

Figure 2. The effects of various prostaglandins (100 nM) on PC and PA activities released by rabbit alveolar macrophages stimulated with lymphocyteconditioned medium. Activities are expressed as \% of control values of cells cultured in parallel with LCM alone. Mean \pm SEM, $\mathrm{N}=5$. Data are expressed as in Figure 1. TOP: Of the 5 prostaglandins examined, only $\mathrm{PGE}_{2}$ stimulated an increase in PC activity, reversing the effects of indomethacin.

BOTTOM: Both $\mathrm{PGE}_{2}$ and $\mathrm{PGE}_{1}$ markedly suppressed PA activities of cell lysates and incubation media, but the other prostaglandins had no effect. 
$\mathrm{PGD}_{2}$, and the synthetic thromboxane mimic $\mathrm{ddPGF}_{2} \alpha$. In all cases, concentrations ranging from 1 to $10,000 \mathrm{nM}$ were evaluated, and representative results $(100 \mathrm{nM})$ are shown in Figure 2 . Only $\mathrm{PGE}_{2}$ could reverse the effect of indomethacin on $\mathrm{PC}$ activity (Figure $2 \mathrm{~A}$ ), while both $\mathrm{PGE}_{2}$ and $\mathrm{PGE}_{1}$ suppressed expression of PA activity (Figure $2 \mathrm{~B}$ ), indicating these effects are specific to prostaglandins of the $E$ series.

During these studies, we noted that LCM caused a slight but relatively consistent decrease in PA activity. In a prior study, another lot of LCM prepared in identical fashion caused modest increases in PA activity (19). In light of the potent suppressive effects of even $1 n M P_{2} E_{2}$, we sought to determine if the variability between lots of LCM could be explained by presence of trace amounts of $\mathrm{PGE}_{2}$. Indeed, the LCM preparation used in this study contained $0.1 \mathrm{nM}$ immunoreactive $\mathrm{PGE}_{2}$ by radioimmunoassay, raising the possibility that trace contamination with $\mathrm{PGE}_{2}$ could have influenced the effect of LCM on macrophage PA activity.

Effects of $\mathrm{PGE}_{2}$ on PMA-stimulated macrophages. We sought to determine if $\mathrm{PGE}_{2}$ had similar modulating effects on macrophages maximally stimulated by PMA, which unlike LCM stimulates marked increases in both PC and PA activities. The addition of indomethacin $(1 \mu \mathrm{M})$ consistently and significantly $(\mathrm{p}<0.05)$ reduced the $\mathrm{PC}$ activity of PMA-stimulated macrophages, although the remaining activity was still much higher than unstimulated cells (Figure $3 \mathrm{~A}$ ). $\mathrm{PGE}_{2}$ and $\mathrm{PGE}_{1}$ completely reversed the suppressive effects of indomethacin, while $\mathrm{PGF}_{2} \alpha$ had no effect. Indomethacin caused a $38 \%$ increase in PA activity released by PMA-stimulated cells $(p<0.05)$
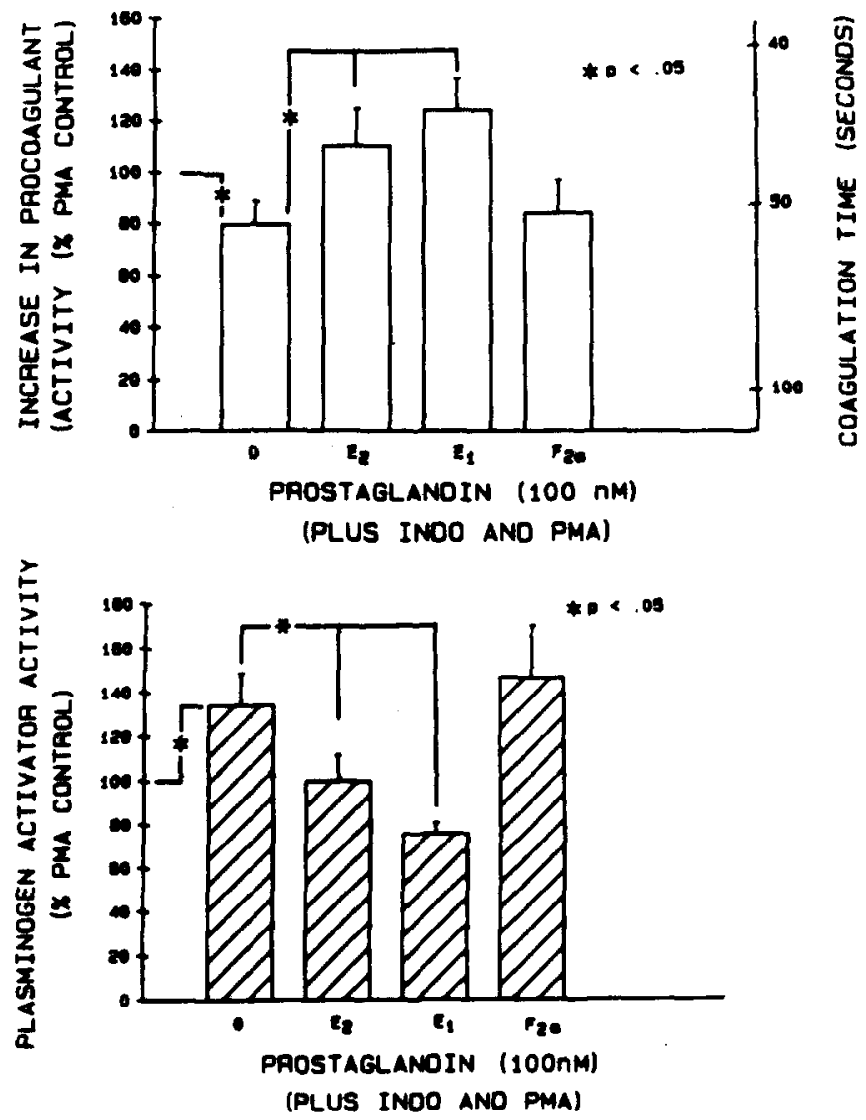

Figure 3. The effects of indomethacin and PG's (100 nM) on PC and PA activities of rabbit alveolar macrophages maximally stimulated with PMA (10 nM). Data are expressed as \% of control values from cells incubated with PMA alone. Mean \pm SEM, $N=4$. Differences between bracketed groups for which $\mathrm{p}<.05$ are denoted by an asterisk. TOP: PC activity. The increase in $P C$ activity above that of freshly harvested cells is displayed on the ordinate at the left. Corresponding coagulation times are shown on the ordinate at the right (log scale). Indomethacin suppressed the augmentation of PC activity of PMA-treated cells by $20 \%$. Addition of either $\mathrm{PGE}_{2}$ or $\mathrm{PGE}_{1}$ completely reversed this effect. In contrast, PGF $_{2} \alpha$ had no effect on PC activity.. BOTTOM: PA activity. Indomethacin stimulated a $38 \%$ increase in PA activity released into incubation media. This effect was also reversed by $\mathrm{PGE}_{2}$ and $\mathrm{PGE}_{1}$, but not $\mathrm{PGF}_{2} \alpha$. 
Again, this effect was reversed by $\mathrm{PGE}_{2}$ and $\mathrm{PGE}_{1}$, but not $\mathrm{PGF}_{2} \alpha$ (Figure 3B). Although the changes induced by indomethacin and PGE were smaller in proportion to the high levels of these activities stimulated by PMA, these results are qualitatively similar to those of LCM-treated cells.

To determine if products of the lipoxygenase pathway can also alter macrophage PC and PA activities, cells were treated with the semiselective lipoxygenase inhibitors NDGA $(1 \mu \mathrm{M})$ or nafazatrom $(1 \mu \mathrm{M})$. When used in doses that should not significantly inhibit cyclooxygenase activity (27), neither agent had any consistent effect on either PC or PA activity of normal or LCMtreated cells (not shown). Further, addition of $\mathrm{LTB}_{4}$ and $\mathrm{LTC}_{4}(0.1-10 \mathrm{nM})$ had no significant effect on either activity in normal macrophages or in cells submaximally stimulated with PMA (2 nM) (not shown). Taken together, these results suggest that leukotrienes have considerably less effects, if any, on these macrophage functions compared to prostaglandin $E_{2}$.

Role of cAMP in PGE 2 -Mediated Effects on PC and PA Activities. To determine if PGE modulates macrophage $P C$ and $P A$ activities by altering adenylate cyclase activity $(28,29)$, we first examined the effect of $\mathrm{PGE}_{2}$ on intracellular levels of $\mathrm{CAMP}$. The addition of $\mathrm{PGE}_{2}(100 \mu \mathrm{M})$ to normal macrophages cultured for 60 minutes increased intracellular levels of cAMP by $77 \pm 30 \%$, compared to control values $(p<0.05)$. Experiments were then performed to determine if exogenous cAMP could mimic the effects of PGE 2 on PC and PA activities. Dibutyryl cAMP (dbcAMP; $1 \mu \mathrm{M}$ to $1 \mathrm{mM}$ ) was added to standard macrophage cultures for 24 hours. As shown in Figure 4, an optimal concentration of db-cAMP $(1 \mathrm{mM})$ acted like $\mathrm{PGE}_{2}$ in decreasing release of PA activity by both normal macrophages $(42 \%$ control; $p<0.05)$ and cells submaximally stimulated by 2 nM PMA ( $57 \%$ control; $\mathrm{p}<0.01$ ). Lysate PA activities were similarly decreased by $57 \%$ and $59 \%$ ( $<<0.01$ ), respectively (not shown). However, db-cAMP had no consistent effect on PC expression by normal or PMA-stimulated macrophages.

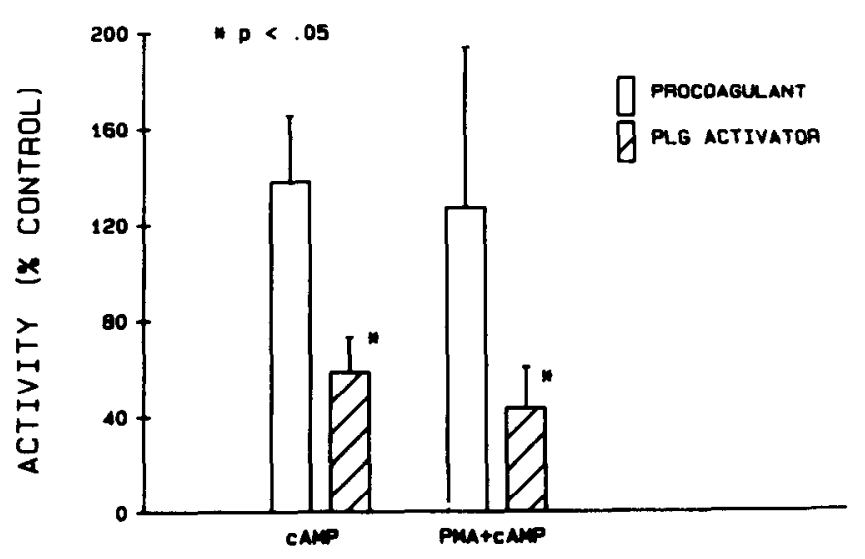

Figure 4. The effect of dibutyryl cyclic-AMP ( $1 \mathrm{mM}$ ) on procoagulant activities of cell lysates and plasminogen activator activities released into media by rabbit alveolar macrophages. Mean \pm SEM, $\mathrm{N}=6$. Data are expressed as \% of their respective control values of cells incubated in either medium alone or in the presence of PMA (2 $\mathrm{nM})$. Dibutyryl-cAMP suppressed released PA activities of unstimulated and PMA stimulated macrophages by $48 \%$ and $52 \%$, respectively ( $\mathrm{p}<$ $0.05)$. db-cAMP had no consistent effect on PC activity in either group.

\section{DISCUSSION}

Interactions between mononuclear phagocytes and the coagulation and fibrinolytic pathways appear to have a role in the pathogenesis of delayed-type hypersensitivity and other inflammatory conditions $(30,31)$. Expression by macrophages of both procoagulant and plasminogen activator activities are augmented in vitro by activated lymphocytes or their products (32-35). Similarly, stimulation of both monocyte plasminogen activator and procoagulant activity has been shown to be in vitro correlates of cell mediated immunity in vivo $(34,35)$. The competing interplay between procoagulant and fibrinolytic activity may regulate local accumulation of fibrin matrix. These fibrin 
matrices potentially contribute to many aspects of inflammatory responses, as fibrinogen-derived products are chemotactic for leukocytes, inhibit lymphocyte function, affect macrophage mobility, and provide a favorable substrate for ingrowth of fibroblasts (35-39). We therefore sought to expand on earlier observations $(17,20,21)$ by examining the effects of arachidonic acid metabolites on concurrent expression of tissue thromboplastin and plasminogen activator activities by rabbit alveolar macrophages.

We found that indomethacin suppressed augmentation of PC activity of LCM and PMA-treated macrophages, while stimulating both released and cell-associated plasminogen activator activity (Figures 1 and 3). These effects of indomethacin could only be reversed by addition of exogenous PGE and not by any other cyclooxygenase metabolite tested (Figure 2). This indicates that indomethacin affects macrophage PC and PA activities by blocking endogenous production of $\mathrm{PGE}_{2}$. Exogenous $\mathrm{PGE}_{2}$ enhanced $\mathrm{PC}$ suppression beyond the level of maximal stimulation by LCM alone, while the same concentrations markedly suppressed PA activity. $\mathrm{PGE}_{2}$ had a qualitatively similar but smaller effect on the markedly elevated PC and PA activities of PMAstimulated macrophages. It is notable that $\mathrm{PGE}_{2}$ only augmented $\mathrm{PC}$ activity of cells that were conditioned by a second stimulus, but suppressed PA production by both normal and conditioned macrophages. Thus, $\mathrm{PGE}_{2}$ may have differential effects on these two activities depending on the degree to which macrophages are co-stimulated with inflammatory mediators.

Most of the effects of $\mathrm{PGE}_{2}$ on leukocyte functions are presently believed to occur by stimulating adenylate cyclase activity $(28,29)$. This prompted us to consider whether intracellular cAMP levels ultimately regulate expression of PC and PA activities. Treating normal or PMAconditioned macrophages with dibutyryl cAMP caused only a variable and statistically insignificant increase in PC activity, but suppression of PA was comparable to the maximal effect of $\mathrm{PGE}_{2}$ (Figure 4). However, it is clear that augmentation of intracellular cyclic AMP is not a sufficient explanation for the effects of $\mathrm{PGE}_{2}$, as we have found that stimulating these cells with adenosine analogues under identical culture conditions causes a similar increase in intracellular cyclic AMP, but opposite directional changes in both PC and PA activites (40). Thus, it appears that modulation of adenylate cyclase activity is either compartmentalized to agonist-specific sites, or alternatively, $\mathrm{PGE}_{2}$ may affect cellular functions by mechanisms unrelated to cyclic AMP.

The modulation by $\mathrm{PGE}_{2}$ of both tissue thromboplastin and plasminogen activator activities is certainly consistent with a growing body of evidence that mononuclear phagocytes exert feedback inhibition on many effector functions through endogenous secretion of $P G E_{2}$. This arachidonic acid metabolite is known to have suppressive effects in vitro on macrophage proliferation, production of complement proteins and oxygen metabolites (1-6), and more recently, expression of histocompatibility antigens, and release of interleukin-1 and tumor necrosis factor (7-9). In contrast, $\mathrm{PGE}_{2}$ enhances expression of $\mathrm{Fc}$ receptors and collagenase production while phagocytosis and tumor killing are variably affected (10-15). Some of these effects may be responsible for the modulation of cell mediated immune reactions by arachidonic acid metabolites in vivo (16).

To summarize, we have shown that $\mathrm{PGE}_{2}$ has opposite modulating effects in vitro on expression by rabbit alveolar macrophages of tissue thromboplastin and plasminogen activator activities. These combined effects may interact to promote fibrin accumulation at inflammatory foci. If this is so, this would establish PGE 2 as an important mediator interrelating the processes of inflammation and coagulation/fibrinolysis. These results further suggest that cyclooxygenase inhibitors and exogenous $\mathrm{PGE}_{2}$ may be useful in future studies to investigate the role of fibrin matrix deposition in the pathogenesis of inflammation and tissue repair. Finally, it is clear that the potential influences of contaminating or endogenously produced $\mathrm{PGE}_{2}$ must be considered in future studies of macrophage procoagulant and plasminogen activator activities.

\section{ACKNOWLEDGMENTS}

Supported by funds from NHLBI grant 1K08-HLO1332-01 and the American Lung Association. Dr. Hasday was supported by an American Lung Association Research fellowship. The authors wish to thank Steven L. Kunkel, Ph.D., for his helpful advice and criticisms. 


\section{REFERENCES}

1. DEMENKOFF, J.H., ANSFIELD, M.J., KALTREIDER, H.B., and ADAM, E. Alveolar macrophage suppression of canine bronchoalveolar lymphocytes: the role of prostaglandin $\mathrm{E}_{2}$ in the inhibition of mitogen responses $J$. Immunol 124, 1365-1370, 1980.

2. GORDON, D., BRAY M.A., and MORLEY.J. Control of lymphokine secretion by prostaglandins Nature 262, 401-402, 1976.

3. CHENSUE, S.W., and KUNKEL S.L. Arachidonic acid metabolism and macrophage activation Clin. Lab. Med. 3, 677-694, 1983.

4. PELLUS, L.M., BROXMEYER, H.E., KURLAND, J.L., and MOORE, M.A.S.

Regulation of macrophage and granulocyte proliferation J. Exp. Med. 150, 277-292, 1979.

5. LAPPIN, D.F., and WHALEY, K. Prostaglandins and prostaglandin synthesis inhibitors regulate the synthesis of complement components by human monocytes Clin. Exp. Immunol. 49, 623-630, 1982.

6. WEIDEMANN, M.J., PESKAR, B.A., WROGEMANN, K., RIETSCHEL, E.T., STANDINGER, H., and FISHER, H. Prostaglandin and thromboxane synthesis in a pure macrophage population and the inhibition by E-type prostaglandins of chemiluminescence FEBS Lett. 89, 136-140, 1978.

7. KUNKEL, S.L., CHENSUE, S.W., PLEWA, M., and HIGASHI, G.I. Macrophage functions in the Schistosoma mansoni egg-induced pulmonary granuloma: role of arachidonic acid metabolites in macrophage Ia antigen expression Am. J. Pathol. 114, 240-249, 1984.

8. KUNKEL, S.L., WIGGINS, R.C., CHENSUE, S.W., and LARRICK, J. Regulation of macrophage tumor necrosis factor production by prostaglandin $\mathrm{E}_{2} J$. Biochem. Biophys. Res. Comm. 137, 404-410, 1986.

9. KUNKEL, S.L., CHENSUE, S.W., PHAN, S.H. Prostaglandins as endogenous mediators of interleukin 1 production J. Immunol. 136, 186-192, 1986.

10. RAZIN, E. and GLOBERSON, A. The effect of various prostaglandins on plasma membrane receptors and function of mouse macrophages Adv. Exp. Med. Biol. 114, 415419, 1979.

11. WAHL, L.M., OLSEN, C.E., SANDBERG, A.L., and MERGENHAGEN, S.E. Prostaglandin regulation of macrophage collagenase producuction Proc.Natl. Acad.Sci. 74, 4955-4958, 1977.

12.. RAZIN, E., BAUMINGER, S., and GLOBERSON, A. Effect of prostaglandins on phagocytosis of sheep erythrocytes by mouse peritoneal macrophages $J$. Reticuloendothel. Soc. 23, 237-242, 1978.

13. OROPEZA-RENDEN, R.L., SPETH, V., HILLER, G., WEBER, K., and FISCHER, H. Prostaglandin $E_{1}$ reversibly induces morphologic changes in macrophages and inhibits phagocytosis Exp. Cell Res. 119, 365-371, 1979.

14. TAFFET, S.M., and RUSSEL, S.W. Macrophage-mediated tumor cell killing: regulation of expression of cytolytic activity by prostaglandin E J.Immunol. 126, 424-447, 1981.

15. DRYSDALE, B.E., and SHIN, H.S. Activation of macrophages for tumor cell toxicity: identification of indomethacin sensitive and insensitive pathways $J$. Immunol 127, 760-765, 1981. 
16. KUNKEL, S.L., and CHENSUE, S.W. Prostaglandins and the regulation of the immune response Advances Inflammation Res. 7, 93-109, 1984.

17. SITRIN, R.G., KALTREIDER, H.B., and GOLDYNE, M.E. Prostaglandin E is required for the augmentation of LPS-stimulated rabbit alveolar macrophage procoagulant activity $J$. Immunol. 132,,867-871, 1984.

18. UNKELESS, J.C., GORDON, S., and REICH, E. Secretion of plasminogen activator by stimulated macrophages J. Exp. Med. 139, 834-850, 1974.

19. SITRIN, R.G., BRUBAKER, P.G., SHELLITO, J.E., and KALTREIDER, H.B. The distribution of procoagulant and plasminogen activator activities among density fractions of normal rabbit alveolar macrophages Am. Rev. Respir. 133, 468-472, 1986.

20. HAMILTON, J.A. Regulation of prostaglandin and plasminogen activator production by mouse peritoneal macrophages J. Reticuloendothel. Soc. 30, 115-128, 1981.

21. DRAPIER, J.C., and PETIT, J.F. Involvement of prostaglandins in LPS-mediated regulation of plasminogen activator synthesis by inflammatory macrophages Int. J. Immunopharmacol. 6, 345-350, 1984.

22. SITRIN, R.G., KALTREIDER, H.B., ANSFIELD, M.J., and WEBSTER, R.O. Procoagulant activity of rabbit alveolar macrophages Am. Rev.Respir. Dis. 128, 282-287, 1983.

23. DEUTSCH, D.G., and MERTZ, E.T. Plasminogen purification from human plasma by affinity chromatography Science 170, 1095-1096, 1970.

24. VAITUKATIS, J.L., LEE, C.Y., EBERSOLE, E.R., and LERARIO, A.C. New evidence for an acute role for protein kinase in hCG action Endocrinology 97, 215-222, 1975.

25. ZAR JH. In "Biostatistical Analysis: Second Edition", Prentice-Hall, Inc., Englewood Cliffs, New Jersey, 390-395, 1984.

26. HASDAY, J.D., and SITRIN, R.G. Dipyridamole stimulates urokinase production and suppressses procoagulant activity of rabbit aolveolar macrophages: a possible mechanism of antithrombotic action Blood 69, 660-667, 1987.

27. KUNKEL, S.L., CHENSUE, S.W., MOUTON, C., and HIGASHI, G.I. Role of lipoxygenase products in murine pulmonary granuloma formation $J$. Clin. Invest.74, 514$524,1984$.

28. GEMSA, D., STEGGEMANN, L., TILL, G., and RESCH, K. Enhancement of the PGE 1 response of macrophages by concanavalin A and colchicine J. Immunol. 119, 524-529, 1977.

29. FERNANDEZ-BOTRAN, R., and SUZUKI, T. Properties of prostaglandin-sensitive adenylate cyclase system of a murine macrophage-like cell line $\left(\mathrm{P}_{388 \mathrm{D}_{1}}\right) \mathrm{J}$. Immunol. 133, 2655-2661, 1984.

30. COHEN, S., BENACERRAF, B., MCCLUSKEY, R.T., and OVARY, Z. Effects of anticoagulants on delayed hypersensitivity reactions J. Immunol. 98, 351-358, 1967.

31. HOLDSWORTH, S.R., and TIPPING, P.G. Macrophage-induced glomerular fibrin deposition in experimental glomerulonephritis in the rabbit J. Clin. Invest. 76, 1367-1374, 1985. 
32. EDWARDS, R.L. and RICKLES, F.R. The role of human T cells (and T cell products) for monocyte tissue factor generation J. Immunol. 125, 606-609, 1980.

33. VASSALLI, J.D., and REICH, E. Macrophage plasminogen activator: induction by products of activated lymphoid cells J. Exp. Med. 145, 429-437, 1977.

34. GECZY, C.L., FARRAM, E., MOON, D.K, MEYER, P.A., and MCKENZIE, I.F.C. Macrophage procoagulant activity as a measure of cell-mediated immunity in the mouse $J$. Immunol. 130, 2743-2749, 1983.

35. RAGSDALE, C.G., SWARTZ, K.H., and CASSIDY, J.T. Immune induction of human monocyte plasminogen activator: characteristics of an assay for cell-mediated immunity $J$. Immunol. Methods 79, 13-26, 1985.

36. SENIOR, R.M., SKUGEN, W.F., GRIFFIN, G.L., and WILNER, G.D. Effects of fibrinogen derivatives upon the inflammatory response: studies with human fibrinopeptide $B$ J. Clin. Invest. 77, 1014-1019, 1986.

37. EDGINGTON, T.S., CURTISS, L.K., and PLOW, E.F. A linkage between the humostatic and immune systems embodied in the fibrinolytic release of lymphocyte suppressive peptides J. Immunol. 134, 471-477, 1986.

38. CIANO, P.S., COLVIN, R.B., DVORAK, A.M., MCDONAGH, J., and DVORAK, H.F. Macrophage migration in fibrin gel matrices Lab Invest. 54, 62-70, 1986.

39. COLVIN, R.B. Fibrinogen-fibrin interactions with fibroblasts and macrophages Ann. N.Y. Acad. Sci. 408, 621-633, 1983.

40. HASDAY, J.D., and SITRIN, R.G. Adenosine receptors on rabbit alveolar macrophages: binding characteristics and effects on cellular function. J. Lab Clin. Med. 110, 264-273, 1987 